\title{
LAS FUENTES SOBRE CLÍSTENES Y LA CRÍTICA
}

The authoress tries to demonstrate that Cleisthenes was not the demagogue who became democrat after being defeated by Isagoras, according to different modern authors, but a real democrat who was always against tyranny and was planning a political and social reform during his exile.

Dentro de la avaricia de las fuentes sobre Clístenes el Alcmeónida ${ }^{1}$, hay dos que, aunque también concisas y breves, son coincidentes en el punto que narra la entrada en política de este reformador: Heródoto, V 66, 69, 72, y Athenaion Politeia (Ath. Pol.) de Aristóteles 20,1-4 y 21,1-2. Ambas ponen en el escenario político de Atenas, a raíz del derrocamiento de la tiranía, dos líderes frente a frente: Iságoras, de tendencia oligárquica, y Clístenes el Alcmeónida. Y lo hacen con una semejanza tal, que Aristóteles parece estar copiando a Heródoto. Sin embargo en algún caso Aristóteles añade al historiador variantes que pueden ayudar a comprender la tesis que aquí se quiere mantener respecto a Clístenes.

1 Asi Tucidides, I 126 y VI 59, que ni siquiera menciona a Clístenes; así también Plutarco, Pericles 3,2, donde Clístenes es meramente el destructor de la tirania y autor

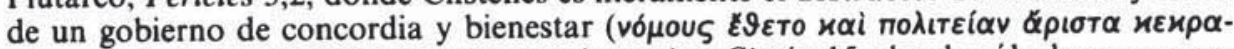

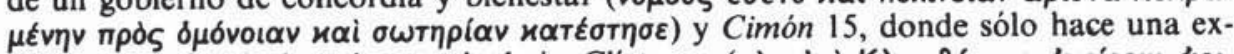

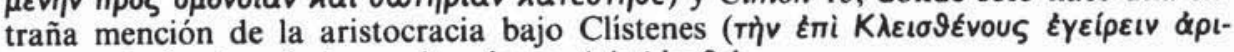
бтократі $\alpha v$ ), o la más breve cita aún en Aristides 2,1.

Lógicamente la concisión sobre Clístenes es aún mayor en los no historiadores. Isócrates es una excepción, pero tampoco se excede en noticias sobre la obra del Alcmeónida. Le sitúa detrás de Solón en Areopagitico (VII) 16-17: (Evitaremos los males pre-

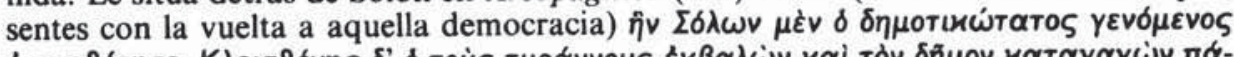

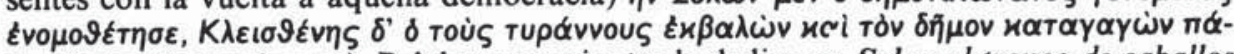

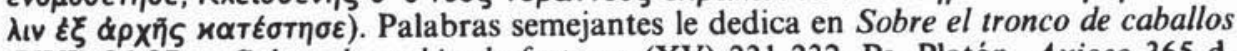
(XVI) 26-27, y Sobre el cambio de fortunas (XV) 231-232. Ps. Platón, Axioco 365 d,

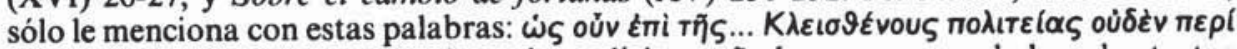
$\sigma \varepsilon$ ห⿻่dv $\eta v$. Los escolios, aun los más explícitos, añaden pocas novedades a los textos aquí mencionados de Heródoto y Aristóteles, salvo er escolio a Elio Arístides, Panatenaico 120,6 , Dindorf III, 1964, pp. 116-118, que da el importante dato de la salida de 


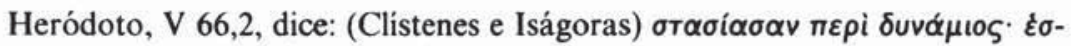

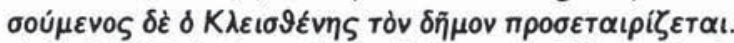

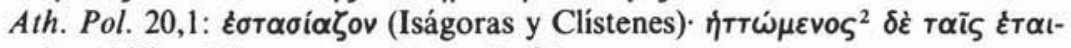

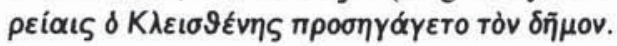

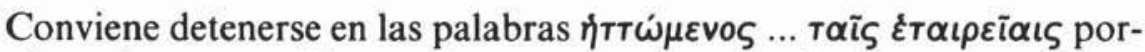
que de su interpretación puede, en parte, depender la que se va a dar a otro pasaje de Heródoto que analizaremos después y que es objetivo prin-

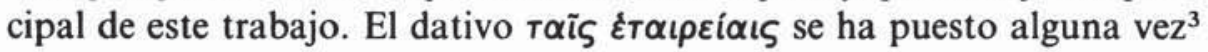

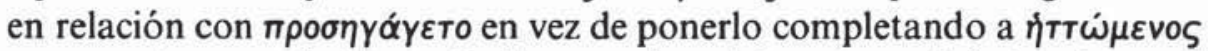

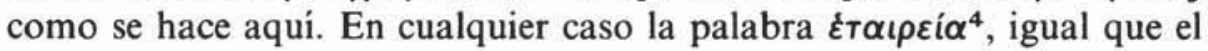

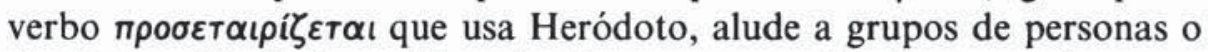
séquito partidario de un líder, séquito que en aquellos tiempos cabe suponer tendría derivaciones, bien políticas, bien de otro tipo, según momentos y circunstancias.

En cuanto a $\dot{\eta} \tau \tau \dot{\omega} \mu \varepsilon v o \varsigma$ se lo ha traducido en general hasta ahora por

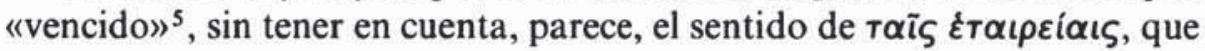

Clístenes al destierro en tiempos de Hipias. La cita de Eliano, Historias Varias XIII 24,5 , se reduce a presentar a Clístenes víctima de su propia medida, el ostracismo.

En los demás (Libanio, Apología de Sócrates 82, y Cicerón, República II 1,2) sólo merece el título de legislador detrás de Solón. Cicerón, Brutus VII 27, le da también a Clístenes el título de orador. Es Pausanias I 29,6, quien aporta el escueto, pero valioso, dato de que Clístenes creó las tribus que aún persisten en su época.

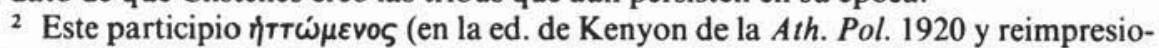

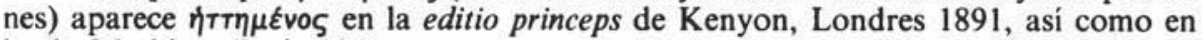
la de Mathieu, París $1941_{2}$, autor que ya anteriormente habia afirmado (Aristote, Constitution d'Athènes. Essai sur la méthode suivie par Aristote dans la discussion des textes, París 1915, p. 55, n. 4): «No creo que la autoridad de Heródoto baste para ha-

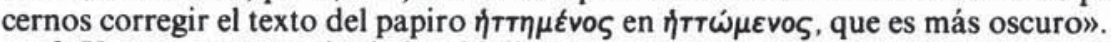

3 Ver esta sugerencia de Maddoli en P.J. Rhodes, A Commentary on the Aristotelian Ath. Pol., Oxford 1981, p. 243.

4 No es fácil seguir la evolución en cuanto a cometido de las éraıpeíaı desde su posible equivalencia primitiva a fratria (Hignett, A History of the Athenian Constitution, Oxford 1970s, p. 58) y más tarde acaso "camarilla de amigos» (Heródoto V 71:

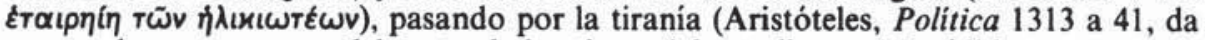
a entender que no eran del gusto de los tiranos) hasta llegar a Tucídides, que parece distinguir (VIII 54) dos épocas: la anterior a él, en que sus miembros probablemente se ayudaban en litigios ante tribunales y en elecciones a cargos, y la que hubo después

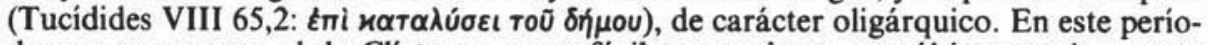
do que nos ocupa, el de Clístenes, no es fácil que tuvieran este último matiz, aparte de otras razones, porque todavía no había democracia. Tampoco aclara mucho en este aspecto el papel que las asigna Isócrates (Panegírico IV 79) de colaboración con el pueblo y no en provecho particular. En Andócides (IV 4) aparecen con incidencia también en las ostracoforias. Otros cometidos se deducen de Tucídides (III 82,5) y Platón (República $365 \mathrm{~d})$.

s "Vencido por las asociaciones» es la traducción en Tovar, Constitución de Atenas, Madrid, reimp. 1970, y en Mathieu-Haussoullier, París $1941_{2}$, si bien aquí se ve 


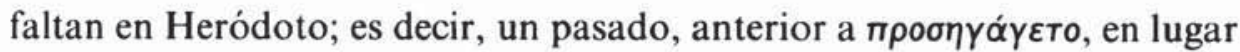
de considerarlo como un presente actual o continuo. Los que traducen

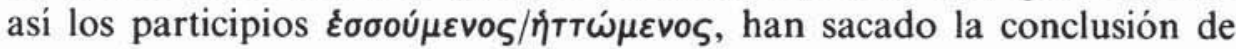
que hubo entre Iságoras y Clístenes una lucha o confrontación previa por conseguir una determinada meta concreta, que ellos suponen fue el arcon$\operatorname{tado}^{6}$. Asi ya G. Mathieu ${ }^{7}$ dio por supuesto que Clistenes se vuelve al demos después de esta derrota frente a Iságoras: «(Clístenes) devenant démocrate seulement après avoir été vaincu par Isagoras...». Y este autor puede haber sido el modelo de otros que recientemente han dado la misma interpretación. Hignett ${ }^{7}$ ha dejado escrito: "(Clistenes) was driven by his failure in the struggle against Isagoras to appeal to demos». Casi la misma idea repite en p. 125: «In the summer of 508, Isagoras won the first round by his election to the archonship. According to Herodotus $(\mathrm{V} 66,2)$ it was when Kleisthenes was worsted in the struggle for power that 'he took the demos into partnership'».

Chr. Meier ${ }^{7}$ : «Hérodote (V 66,2) rapporte qu'il (Clistenes) fut vaincu dans un combat contre Isagoras et qu'après sa defaite il s'est tourné vers le peuple $(\delta \tilde{\eta} \mu \circ \varsigma)$ ".

Jochen Martin 7 : «Isagoras wird für das Jahr 508/7 zum Archon gewählt. Kleisthenes wendet sich daraufhin, wie Herodotos und Aristoteles berichten, ans Volk...".

A. Andrewes?: "(Herodoto V 66,2 dice) that he (Clistenes) brought the people over his side because he had been defeated in a struggle for power against Isagoras».

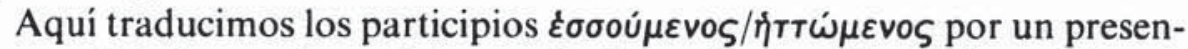

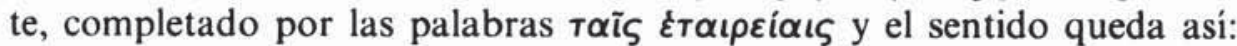
"Clístenes, siendo inferior o estando en inferioridad de adictos, trató de atraer hacia sí al demos». Este sentido se ve respaldado por las palabras

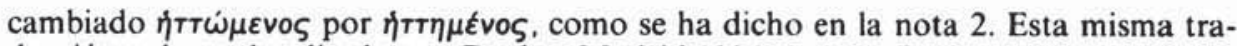
ducción se lee en la editada por Gredos, Madrid 1984, a cargo de Manuela García Valdés.

- El arcontado de Iságoras aparece implicado en estos acontecimientos en Athenaion Politeia 21,1; y Dionisio de Halicarnaso, R.A. I 74,6 y V 1,1, sitúa este arcontado en el primer año de la 68 Olimpiada (408/7 a.C.). De la unión de estas dos fuentes, Ath. Pol. y Dionisio de Halicarnaso, puede haber salido la conjetura de que Clístenes e Iságoras luchaban por esa Magistratura.

7 G. Mathieu, Aristote, Constitution d'Athènes. Essai sur la méthode... (ver nota 2); Hignett (o.c. en nota 4), p. 156, n. 2; este autor repite las mismas ideas en pp. 125 y 126; Christian Meier, "Clisthène et le problème politique de la polis grecque», RIDA 20, 1973, pp. 115-119, espec. 133 y n. 57; Jochen Martin «Von Kleisthenes zu Ephialtes...» Chiron IV, 1974, pp. 5-42, espec. 7; A. Andrewes «Kleisthenes' Reform Bill» $C Q 27,1977$, pp. 241-248, espec. 241. 
que las mismas fuentes (Heródoto y $\mathrm{Ath}$. Pol.) expresadas arriba añaden

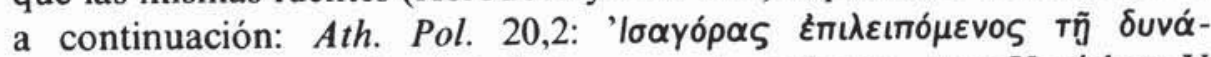
$\mu \varepsilon \iota_{. . .}=« I$ ságoras quedando inferior en poder o fuerza....; y Heródoto $\mathrm{V}$

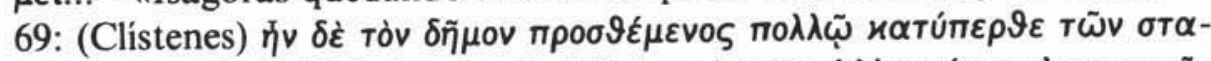

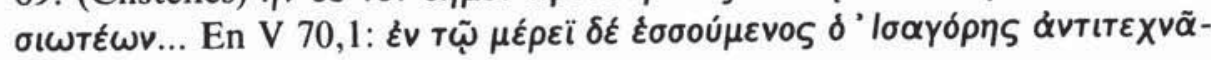
$\tau \alpha \iota \tau \alpha \dot{\delta} \delta \cdot \ldots$

Si la inferioridad de Clístenes, a que aluden los textos presentados al principio, se debiera a que Iságoras, y no él, obtuvo el arcontado, no dirían a continuación, siendo Iságoras arconte, que éste estaba en inferioridad de poder respecto de Clístenes, ni tampoco éste sería superior a sus rivales como dice Heródoto, estando éstos en el poder.

$\mathrm{La}$ inferioridad de Clístenes en adheridos políticos se comprende muy bien, si se tiene en cuenta que pasó sus tiempos jóvenes en el destierro por luchar contra la tiranía, y, concretamente, los años que precedieron al derrocamiento de ésta ${ }^{8}$. Iságoras en cambio se quedó en Atenas durante el régimen tiránico (Heródoto, V 70,1, dice que hospedó en su casa a Cleómenes cuando éste puso sitio a los tiranos) y tendría al acabar éste toda su camarilla política y demás dispositivos en orden y a punto. Una prueba de ello es que cuando Cleómenes invadió el Ática llamado por Iságoras, encontró enseguida trescientos partidarios de éste para formar un Conse-

8 El primer destierro conocido de esta familia tuvo lugar con motivo de la represión en la intentona de Cilón: Plutarco, Solón 12; Tucídides I 126; Epitome de Heraclides 4 , recogido en varias ediciones de Ath. Pol.: ver entre otras, Tovar (o.c. en nota 5), p. 45 , fr. 8; Kenyon, Oxford $1976_{2}$, p. 73 , fr. 2. El segundo se produjo al triunfar definitivamente Pisístrato (Heródoto I 64,3 y Plutarco, Solón 30). El tercero, sufrido en tiempos de Hipias, según el escolio a E. Arístides (Panatenaico 120, 6, Dindorf III,

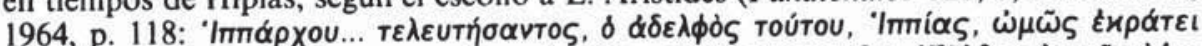

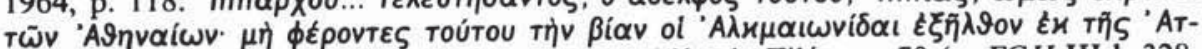

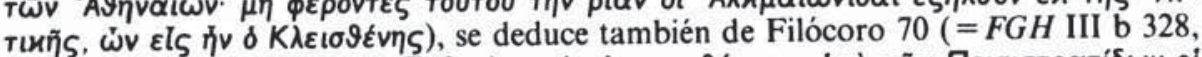

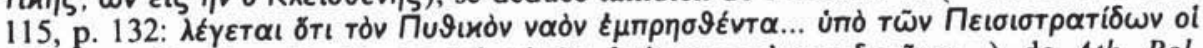

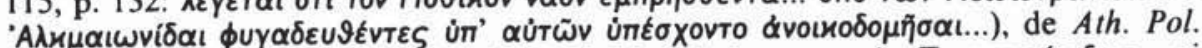

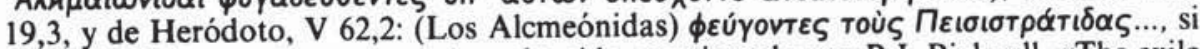
bien este último texto, no muy claro, ha sido cuestionado por P.J. Bicknell, «The exile of the Alcmeionidai...", Historia 19,1970 , pp. 129-131, espec. 130, n. 6, al cual considera falaz modelo del escolio de E. Arístides, antes citado. En consecuencia los Alcmeónidas estarian en su segundo destierro, no en el tercero. Pero si es verdad que Clístenes fue arconte en el año 525/4 (ver nota 13), tuvieron que volver del segundo necesariamente, y es verosímil que lo hicieran cuando Pisístrato, después de su triunfo definitivo, se mostró condescendiente con los que habian faltado (Plutarco, Solón 31, y Ath. Pol. 16,2 ) o en tiempos de la blandura de Hipias, antes del asesinato de Hiparco (Tucídides

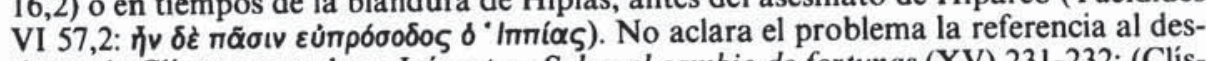
tierro de Clistenes que hace Isócrates, Sobre el cambio de fortunas (XV) 231-232: (Clis-

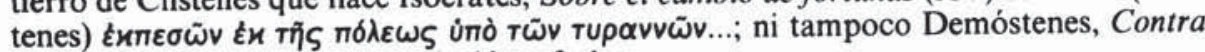
Midias (XXI) 144, ambos sin alusión a fecha concreta. 
jo en sustitución del que el propio Cleómenes acababa de disolver (Heródoto, V 72,1-2, y Ath. Pol. 20,3).

Los que interpretan que Clístenes acudió al demos sólo ante su fracaso en la aspiración al arcontado, tienen motivos para descalificarle como demócrata; pero si, como decimos, Clístenes intentó, al verse con menos adictos, atraer hacia él el mayor número de éstos, su figura será la de un político más o menos aprovechado, pero nada fuera de esto.

Sin embargo, la fama de oportunista adquirida por Clístenes hasta ahora se ha debido, sobre todo, a la interpretación, errónea a nuestro juicio, que se ha dado a otro pasaje de Heródoto que comentamos a continuación, interpretación que, como ya dijimos, puede estar influida por la dada a los textos precedentes de Heródoto y Aristóteles. El pasaje en cues-

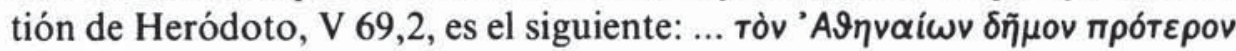

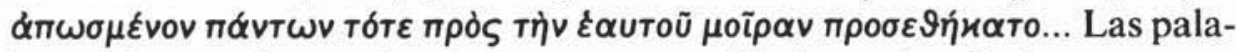

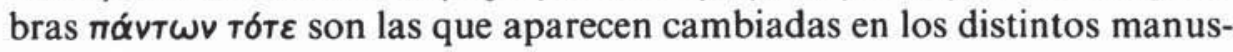
critos, y, como puede observarse, no alteran esencialmente el sentido general que se quiere analizar. Las palabras clave para la distorsión de la

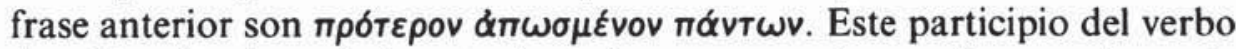
$\alpha \pi \omega \vartheta \hat{\varepsilon} \omega$ ('rechazar', 'apartar', etc.), que es pasivo y sin complemento agente, se ha falsificado doblemente: $1 .^{\circ}$ por traducirlo por «despreciar»; $2 .^{\circ}$ por poner a Clístenes de complemento agente, complemento que no aparece por ninguna parte. $\mathrm{Y}$ así con esta alteración caprichosa Hignett ha escrito ${ }^{9}$ : "(Clístenes) atrajo entonces al pueblo ateniense a su propio partido, aunque previamente le había despreciado (although previously he had spurned them)». La traducción que damos aquí es ésta: "(Clístenes) atrajo entonces al pueblo ateniense, anteriormente apartado de

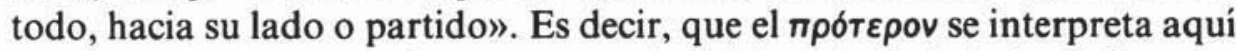
en el sentido de que al demos antes se le había dejado de lado sin intervenir políticamente en el ejecutivo. Este alejamiento del demos de la actividad política puede referirse y remontarse hasta los tiempos de Solón (incluso antes, de acuerdo con Ath. Pol. 2,3: oúdevòs... Éтúyxavov

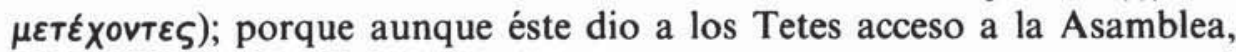

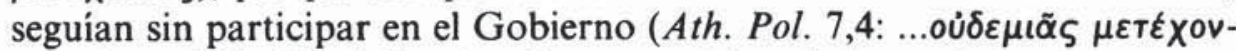
$\tau \alpha \varsigma \alpha \rho \chi \eta \tilde{\zeta})^{9}$ bis. También el $\pi \rho \delta ́ \tau \varepsilon \rho o v$ podría referirse a la anterior etapa de Pisistrato, en que el poder personal del Tirano excluía toda participación efectiva (Ath. Pol. 15,5: «ocupaos de vuestras cosas; de las comunes me ocupo yo").

\footnotetext{
9 Hignett, o.c., p. 125.

9bis Solón, fr. 5 (Adrados, Líricos I, Barcelona 1956, p. 191), dice que no quitó ni dio nada al demos en cuanto a estimación se refiere.
} 
Dietmar Kienast ${ }^{10}$, sin llegar a traducir la frase en cuestión, parece darle un sentido parecido al nuestro cuando dice que Clístenes pudo ganar para sí la gran masa del pueblo ático, masa representada en la Asamblea popular, pero desconectada como factor político en las luchas de partido («beiseite gestossen»). Esta interpretación la da Kienast sobre un texto en que se ven alteradas las dos palabras que hemos subrayado antes, y es una prueba de que, como decimos, el cambio de ellas no altera el sentido.

Pero la distorsión de la frase no empieza con Hignett. Ya Curtius ${ }^{11}$ presenta el texto traducido al latín del siguiente modo: «Plebem, antea a se spretam, nunc totam ad suas partes traduxit». Quizá en esta fuente han bebido los críticos, incluido su compatriota Helmut Berve ${ }^{12}$, que también alude al texto de Heródoto con el sentido de «despreocuparse» del demos en vez de "despreciar», como ha traducido, decimos, Hignett.

Está claro que con esta falsa interpretación de la frase sale un Clistenes muy mal parado, un Clístenes oportunista, caricaturesco, que sólo acude al demos en una situación apurada. Pero a los que dan esta interpretación, a los que, como Hignett, dicen que Clistenes despreció anteriormente al demos, cabe preguntarles: ¿Cuándo estuvo Clístenes en condiciones de favorecer o despreciar al demos? La juventud la pasó en el destierro y, como se ha dicho, en él estaba cuando acabó la tiranía. Si alguna vez volvió del destierro y desempeñó el arcontado en 525/4, como parece deducirse de un trozo de pentélico aparecido hace algunos años en el Ágora de Atenas $^{13}$, hay que suponer qué margen de poder concedía el tirano a un arconte epónimo para tomar iniciativas democráticas. Lo sucedido en Leipsidrion (Ath. Pol. 19,3, y Heródoto, V 62,2) es indicio de lo que se podia intentar bajo la tiranía.

10 Dietmar Kienast, «Die innenpolitische Entwicklung Athens im 6. Jahrhundert und die Reformen von 508", Historische Zeitschrift 200, 1965, pp. 265-283, espec. 271,

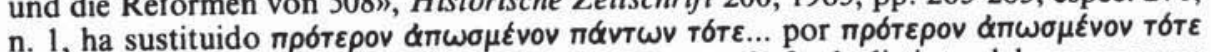
nóviws..., es decir, ha tomado el mismo texto que Oxford, distinto del que usamos aqui, que se ajusta al manuscrito florentino y que ha usado, entre otros, Grote, versión francesa, Histoire de la Grèce, Paris 1864-1867, V, p. 301, con traducción similar a la nuestra.

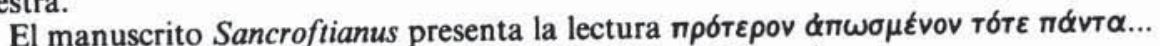
Cf. E. Curtius, Historia de Grecia, II, Madrid 1887, p. 131, n. 1.

11 E. Curtius, obra y lugar citados en nota 10.

12 Helmut Berve, Die Tyrannis bei den Griechen, I, Munich 1967, p. 171.

13 Un trozo de pentélico aparecido el 5 de mayo de 1936 en el Ágora de Atenas y fechado hacia finales del s. v a.C., contiene una relación de nombres, que se interpreta como una lista de arcontes. En ella figura Clístenes, aunque no muy claramente $[(K) \lambda \varepsilon เ \sigma \vartheta \varepsilon v(\varepsilon \varsigma)]$, escrito antes de Milcíades. Como Milcíades fue arconte en 524/3, según Dionisio de Halicarnaso (VII 3), a Clístenes le correspondería ser arconte en 525/4. 
El pasaje en cuestión de Heródoto ( $\mathrm{V}$ 69,2) no refleja otra cosa que el momento de poner en práctica Clístenes lo que ya traía planeado en sus muchos años de destierro (ver nota 8). La situación de inferioridad al volver de éste, inesperada tal vez por él, pudo sin duda precipitar los acontecimientos. Clístenes, que había luchado siempre con su clan frente a la tiranía (Ath. Pol. 20,4), consideraría normal, al desaparecer ésta, ser aclamado por todos como el libertador. Pero se interpuso Iságoras, que, invadido por los esquemas oligárquicos de sus antepasados los pedieos, quería poner el reloj político, como suele decirse, con cuarenta años de retraso. Y esta situación, decimos, fue lo que provocó eso que Hignett (o.c., p. 126) ha llamado "Kleisthenes' sensational volte-face», es decir, esta situación fue lo que puede llamarse causa desencadenante, no determinante, de una reforma muy pensada y planificada anteriormente; fue la $\pi \rho \delta \phi \alpha \sigma ı \varsigma$, no la $\alpha i t i ́ \alpha$, para usar las palabras de Tucídides, I 23,5.

$\mathrm{Si}$, como quiere Hignett (o.c., p. 125), "when Kleisthenes first came back from exile he has not planning a democratic reform", si solamente el fracaso ante Iságoras le decidió a plantear al demos su reforma, entonces sería Clístenes, a la vez que el prototipo de demagogo y oportunista, el privilegiado talento sobrehumano que en una operación cerebral relámpago improvisa una reforma de tal envergadura. Porque está claro que la captación del demos fue simultánea a la exposición de su reforma (Ath.

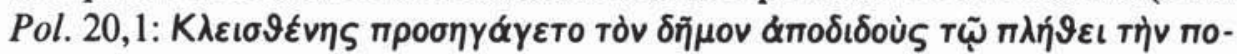

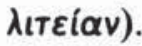

Que en el destierro respirase Clístenes aires reformistas no es nada extraño. En todo el ámbito griego y sus proximidades se fraguaban por aquella época innovaciones de todo tipo, incluidas las políticas., El binomio o antinomia $\varepsilon \sigma \vartheta \lambda \delta \varsigma / \varkappa \alpha \varkappa \delta \varsigma$, con alguna vigencia aún en Atenas, había sido en general esterilizado fuera de ella. Sin salirnos de Heródoto tenemos indicios claros de esa efervescencia reformista: en I 70, nos presenta el historiador las ofertas de Tales de Mileto para una reforma centralizadora y a la vez autonómica de las ciudades jonias, cuyo centro sería Teos; en IV 161, habla de la reforma de Demonacte en Cirene; en VI 43, nos cuenta el establecimiento de la democracia en Jonia por el persa Mardonio, y en VII 164, dice que Cadmo de Cos puso el gobierno en manos de los ciudadanos y se retiró a Zancle (Mesana o Mesina). De hacia el año

Si fue Clístenes arconte en esta época, no se ve fácil que aspirase al arcontado de nuevo frente a Iságoras (ver nota 6).

Sobre esta lista de arcontes ver B.D. Meritt, "A early archon list», Hesperia 8, 1939, pp. 59-65, espec. p. $60=S E G 10,352$, y J. Cadoux, "Athenian Archons from Kreon to Hypsichides", JHS 68, 1948, pp. 70-123, espec. 71. 
500 es también la propuesta de isonomía en Mileto por Aristágoras (He-

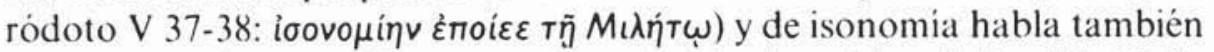
Otanes en el famoso diálogo que muestra el mismo historiador (III 80,6). lgualmente en $\mathrm{V} 92$, Sosicles reprocha el intento de derrocar los regímenes igualitarios, y en III 142, habla de poner el $\alpha \rho x \eta \dot{~ \varepsilon i \varsigma ~ T o ̀ ~} \mu \dot{\varepsilon} \sigma o v$. Por el año 570 disponía ya Quios de una Constitución con al menos una Bulé de 50 miembros por tribu, con Demarcos, etc ${ }^{14}$. Todos estos hechos, si no coinciden exactamente con el destierro de Clístenes, dan una idea del ambiente

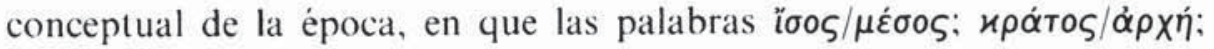
$\delta \tilde{\eta} \mu \circ \varsigma / \pi \lambda \tilde{\eta} \vartheta \circ \varsigma$ aparecen combinadas en las diversas facetas del pensar humano. Si en los casos citados de Heródoto, como en tiempos anteriores

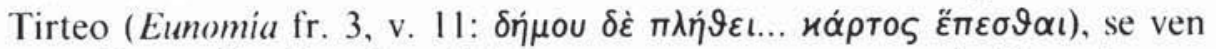
estas ideas aplicadas a la política, en otros poetas se ven referidas a la conducta humana en general: Teognis, Elegías I 220, aconseja el término me-

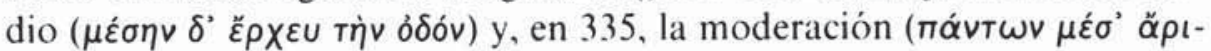
$\sigma \tau \alpha)$ con mención expresa del $\mu \eta \delta \dot{v} v$ ă $\gamma \alpha v$; así también Focílides ${ }^{15}$, Máxi-

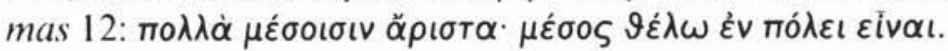

Un médico de hacia el siglo vi, Alcmeón de Crotona, contemporáneo de los Pitagóricos (Aristóteles, Metafisica I 5, 986 a 22-35 y 986 b 1; Diógenes Laercio, VIII 63) aplicará estos conceptos a la salud del cuerpo humano. Para él un cuerpo sano es aquel en el que se logra el equilibrio o isonomia de las fuerzas o humores corporales, mientras que la enfermedad se produciria en la absorción o monarquia de una de ellas: 24 B $4(22)^{16}$

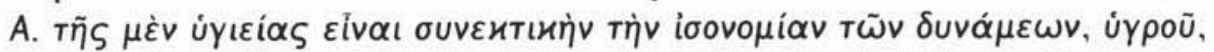

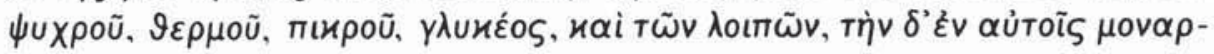

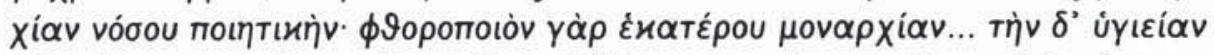

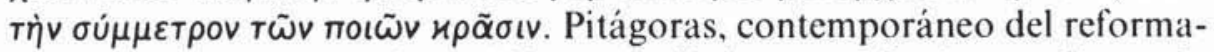
dor Alcmeónida, escapó también como él de su patria, Samos, huyendo de la tirania, según Diógenes Laercio, III 3: (Pitágoras) $\varepsilon \pi \alpha v \dot{\lambda} \lambda \vartheta \varepsilon v \varepsilon i \varsigma \zeta \Sigma \alpha$ -

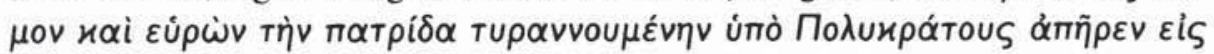

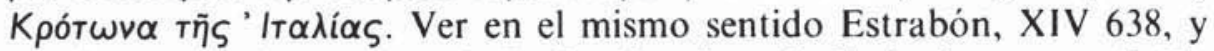
Porfirio, Vida de Pitágoras 9. De los dos tipos de discípulos que tenía Pitágoras en esa especie de hetería que fundo en Crotona, unos, los $\mu \alpha \vartheta \eta$ натьиoi o del círculo interno ${ }^{17}$, parece que practicaban un género de vida

14 L.H. Jeffery, "The Cours of Justice in archaï Chios", BSA 51, 1956, pp. 157-167.

15 Ver Tirteo y Focilides en Adrados, Liricos, I, Barcelona 1956, pp. 132 y 237 respectivamente, y Teognis, ihid., II, Barcelona 1959, pp. 183 y 191.

10 Ver Die Fragmente der Vorsokratiker de H. Diels-W. Kranz, Berlin 1961 $1_{10}$. Cf. Aecio V 30,1.

17 K. von Fritz, Mathematiker und Akusmatiker bei den alten Pythagoreern, $S B A W, 1960$, Heft 11, espec. pp. $4-7$ y 13 ss. 
y costumbres particulares que están también en consonancia con este ambiente general que estamos describiendo. Ver Diógenes Laercio, VIII I,10,

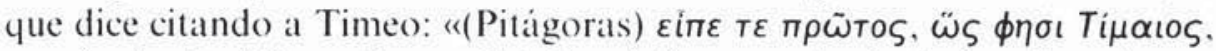

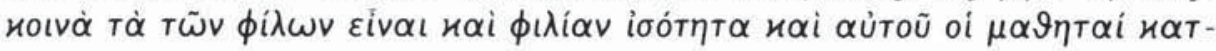

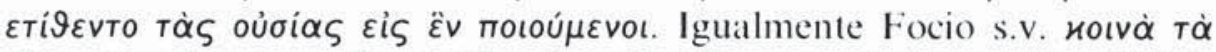

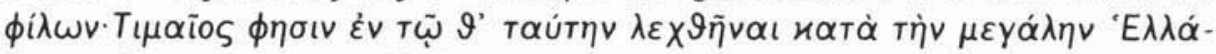

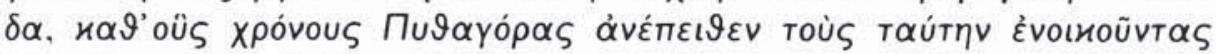

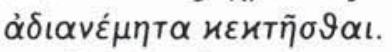

Dentro de este recorrido de influencias ambientales en ('listenes cabe mencionar a Delfos, donde también estuvieron los Alcmeónidas en el destierro (ver en nota 8 anterior Filócoro $70=F G H$ III b 328, 115, p. 132). Fn Delfos habia escritas maximas de moderación como las tan conocidas $\gamma v \tilde{\omega} \vartheta \iota \sigma \varepsilon \alpha u+o ́ v, \mu \eta \delta \dot{\varepsilon} v$ äy $\alpha v$ (Pausanias X 24,1), y de Delfos salieron valticinios reformistas, como la de Fsparta (Plutarco, Licurgo 6; Heródoto, I 65,3 y Tirteo, versos I y 12), la de Demonacte en (irene (Heródoto, IV 156-16.3) y otras aventuras coloniales (el caso de Dorieo, que no consultó a Delfos, aparece en Herodoto, V 42, como algo excepcional), cuyas comunidades se convertian en una especie de laboratorio politico, donde gentes desarraigadas de sus respectivas Polis se veian obligadas a ensayar fórmulas de convivencia acordes con la variopinta indole de los que las formaban. Un ejemplo de esto podria ser la comuna de Lipari ${ }^{18}$, formada por los supervivientes de la guerra de Sicilia, compañeros de Pentatlo de Gnido (Diodoro de Sicilia, V 9).

Añadimos finalmente otro dato que también hace pensar en que la reforma de Clístenes se fraguó en el destierro: el ostracismo que él introdujo en Atenas ( $A$ th. Pol. 22, 1) ${ }^{11}$ estaba también establecido en Argos, Mileto, Mégara, según diversas fuentes (ver Aristóteles, Politica 1302 b 18-19; Jacoby, $F(; H$ III b 328, fr. 30, y escolio a Aristófanes, (ahalleros 855 b).

Que Clístenes lo introdujo, y no lo inventó, se deduce también del ma-

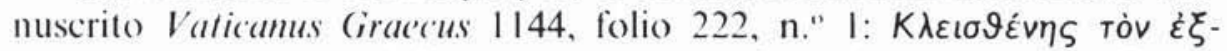

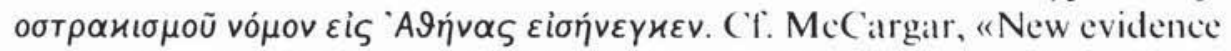
for the Kleisthenic Boule", ( $P$ h 71, 1976, pp. 248-252, espec. 248.

Orin(ia GonZAili:Z DI: I.A Ri:i)

\footnotetext{
18 Sobre la comuna de los compañeros de Pentatlo de Gnido, ver Levêque-Naquet. Clisthene I'Athénie'n, París 1973, p. 69, n. I.

19 Aparte de Ath. Pol. 22,1, dan a Clistenes la autoria del ostracismo en Atenas otras fuentes: véase $F(i / l$ III h 328, fr. 30. Véase también el testimonio del lexicógrafo Claudio Casilo (ed. M.E. Miller, Mélanges de Littérature (irecque, 1868, p. 398) en Raubitscheck, "Theophrastos on ostracism", ('lass. e't Med. 19, 1958, p. 81.
} 